\title{
Mast cells rescue implantation defects caused by c-kit deficiency
}

\author{
K Woidacki ${ }^{1}$, M Popovic ${ }^{1}$, M Metz ${ }^{2}$, A Schumacher ${ }^{1}$, N Linzke ${ }^{1}$, A Teles ${ }^{1}$, F Poirier ${ }^{3}$, S Fest ${ }^{4}$, F Jensen ${ }^{1}$, GA Rabinovich ${ }^{\star, 5,6}$, \\ $M$ Maurer $^{2,6}$ and AC Zenclussen ${ }^{*, 1,6}$
}

Various physiologically relevant processes are regulated by the interaction of the receptor tyrosine kinase (c-Kit) and its ligand stem cell factor (SCF), with SCF known to be the most important growth factor for mast cells (MCs). In spite of their traditional role in allergic disorders and innate immunity, MCs have lately emerged as versatile modulators of a variety of physiologic and pathologic processes. Here we show that MCs are critical for pregnancy success. Uterine MCs presented a unique phenotype, accumulated during receptivity and expanded upon pregnancy establishment. Kit ${ }^{W-s h / W-s h}$ mice, whose MC deficiency is based on restricted $c$-Kit gene expression, exhibited severely impaired implantation, which could be completely rescued by systemic or local transfer of wild-type bone marrow-derived MCs. Transferred wild-type MCs favored normal implantation, induced optimal spiral artery remodeling and promoted the expression of MC proteases, transforming growth factor- $\beta$ and connective tissue growth factor. MCs contributed to trophoblast survival, placentation and fetal growth through secretion of the glycan-binding protein galectin-1. Our data unveil unrecognized roles for MCs at the fetomaternal interface with critical implications in reproductive medicine.

Cell Death and Disease (2013) 4, e462; doi:10.1038/cddis.2012.214; published online 17 January 2013

Subject Category: Experimental Medicine

The interplay between the receptor tyrosine kinase c-Kit (CD117) and its ligand stem cell factor (SCF) is essential for various processes like regulation of proliferation, differentiation and survival of hematopoietic cells, germ cells and melanocytes. ${ }^{1}$ It further promotes cell adhesion, ${ }^{2}$ spermatogenesis, ${ }^{3}$ oogenesis and folliculogenesis. ${ }^{4}$ In many cell types, including $B$ and $T$ cells, the expression of $\mathrm{C}-\mathrm{kit}$ is downregulated upon cell differentiation, suggesting a role of other growth factors like, for example, BAFF (B-cell activating factor) for $\mathrm{B}$ cells ${ }^{5}$ or transforming growth factor- $\beta$ (TGF- $\beta$ ) for $T$ cells ${ }^{6}$ for their development and differentiation. However, mast cells (MCs), natural killer (NK) cells, dendritic cells (DCs) and decidual macrophages retain c-Kit expression. ${ }^{7}$ At the fetomaternal interface, c-Kit is highly expressed in the decidua (maternal part) as well as in the placenta (fetal part). ${ }^{8,9} \mathrm{~A}$ point mutation in the tyrosine kinase domain of the Kit-receptor ${ }^{10}$ in $\mathrm{WBB} \mathrm{F}_{1}-\mathrm{W} / \mathrm{W}^{\mathrm{V}}$ mice results in severe pathologic abnormalities and infertility, ${ }^{11,12}$ whereas an inversion mutation of the kit gene ${ }^{13}$ in $K i t^{W-s h} /$-sh mice has less severe effects, with the mice being reportedly fertile. ${ }^{14}$ Besides their profound deficiency in MC populations, other immune cells are not affected as $K i t^{W-s h / W-s h}$ displayed normal levels of B cells, T cells, macrophages, DCs, peripheral NKs and basophils, ${ }^{15}$ probably due to the expression of C-Kit in the hematopoietic stem cells of $K i t^{W-s h} / W$-sh mice. ${ }^{16}$ Therefore, these mice represent a powerful tool to investigate the influence of MC deficiency, caused by a defective $c$-Kit signaling on pregnancy-relevant processes.

MCs are widely known as effector cells responsible for mediating allergic disorders and innate immunity. However, emerging evidence has identified a central role for these cells in the development and establishment of adaptive immune responses, as they are able to produce a variety of both proand anti-inflammatory mediators. ${ }^{17} \mathrm{MCs}$ are present in the myometrium, endometrium and cervix from humans and rodents, where they preferentially localize around blood vessels. ${ }^{18-22}$ Little is known, however, about the functional contribution of MCs to uterine remodeling and, thus, to

\footnotetext{
${ }^{1}$ Experimental Obstetrics and Gynecology, Medical Faculty, Otto-von-Guericke University, Magdeburg, Germany; ${ }^{2}$ Department of Dermatology and Allergology, Charité-Universitätsmedizin Berlin, Berlin, Germany; ${ }^{3}$ Institut Jacques Monod, CNRS UMR 7592, Université Paris Diderot, 75205 Paris, France; ${ }^{4}$ Department of Paediatrics Haematology and Oncology, Universitätsmedizin Leipzig, Leipzig, Germany and ${ }^{5}$ Laboratorio de Inmunopatología, Instituto de Biología y Medicina Experimental (IByME) and Departamento de Química Biológica, Facultad de Ciencias Exactas y Naturales, Universidad de Buenos Aires, Buenos Aires, Argentina. *Corresponding author: GA Rabinovich, Laboratorio de Inmunopatología, Instituto de Biología y Medicina Experimental (IByME) and Departamento de Química Biológica, Facultad de Ciencias Exactas y Naturales, Universidad de Buenos Aires, Buenos Aires, Argentina. Tel: +54 1147832869 ; Fax: +54 1147862564 ; E-mail: gabyrabi@gmail.com

or AC Zenclussen, Experimental Obstetrics and Gynecology, Medical Faculty, Otto-von-Guericke University, Gerhart-Hauptmann Str. 35, 39108, Magdeburg, SaxonyAnhalt, Germany. Tel: + $493916717460 ;$ Fax: + 49391 6717440; E-mail: ana.zenclussen@med.ovgu.de

${ }^{6}$ These authors contributed equally to this work.

Keywords: pregnancy; implantation; placentation; mast cells; galectin-1

Abbreviations: BAFF, B-cell activating factor; BMMC, bone marrow-derived mast cell; c-Kit, receptor tyrosine kinase (CD117); CtGF, connective tissue growth factor; Fc\&Rl $\alpha$, high affinity lgE receptor; Gal-1, galectin 1; GC, giant cell; gd, gestation day; Mcpt, mast cell protease; MMP, matrix metalloproteinase; PAl, plasminogen activator inhibitor; SCF, stem cell factor; TGF- $\beta$, transforming growth factor- $\beta$; tPA, tissue-type plasminogen activator; uPA, urokinase plasminogen activator; VEGF, vascular endothelial growth factor

Received 11.12.12; revised 13.12.12; accepted 13.12.12; Edited by RA Knight
} 
pregnancy establishment and the mechanisms underlying this effect. As implantation of the blastocyst into the maternal endometrium requires substantial tissue remodeling and MCs are a rich source of biologically active mediators, ${ }^{17,23}$ we hypothesized that MCs may be important players in pregnancy establishment and maintenance.

Early morphological observations suggest an association of MCs and histamine release with ovum implantation. ${ }^{24}$ The in vivo exposure to $\mathrm{MC}$ stabilizers, which inhibit their degranulation, resulted in decreased uterine endothelial cell proliferation and reduced vascular endothelial growth factor-A (VEGF-A) secretion. ${ }^{21}$ In addition, we have recently shown that MCs degranulate in the uterus in response to hormone stimulation. ${ }^{25}$ Pregnant women affected by systemic mastocytosis or asthma exhibit manifestations of preterm labor and delivery. ${ }^{26}$ Recent studies, however, discarded a participation of MCs in the induction of labor in a mouse model. ${ }^{27} \mathrm{We}$ undertook the present study using MC-deficient $K i t^{W-s h} / W$-sh mice, whose MC deficiency is caused by a defective $c$-Kit gene expression, to characterize the role of MCs in pregnancy success and to dissect the mechanisms underlying the modulatory functions of these cells.

\section{Results}

Uterine MC numbers increased during the fertile period of the estrous cycle. We first analyzed the number of uterine MCs throughout the estrous cycle and early pregnancy. MC numbers were highest during the fertile phase of the cycle, namely in estrus when the female is sexually receptive and the endometrium is prepared for nidation (Figures $1 \mathrm{a}$ and $\mathrm{b}$ ). MC numbers were even higher on days 2 and 5 of gestation (Figure 1a), but declined rapidly if fecundation did not occur (metestrus). As mast cell deficiency in $K i t^{W-s h} / W$-sh is caused by a defective $c$-Kit signaling and $c$-Kit/c-Kit ligand interaction is important for oocyte development and folliculogenesis, ${ }^{4}$ we monitored the estrous cycle in these mice. Sexually mature $K i t^{W-s h} / W$-sh showed a normal estrous cycle in respect to time duration with clearly distinguishable phases. Besides, MCs were not critical for ovulation as shown by similar number of corpora lutea in MC-deficient $\mathrm{Kit}^{\mathrm{W} \text {-sh/W-sh }}$ and their wild-type counterparts (Supplementary Figure 1).

\footnotetext{
Uterine MCs revealed a unique phenotype and were located close to blood vessels at implantation sites. We next examined the presence of MCs in allogeneic implantation sites of wild-type mice. MCs locate in between the implantation sites (Figure 1c). At midpregnancy, MCs were present in high numbers at the maternal side of the fetalmaternal interface and in general mainly localized close to blood vessels (Figures 1d and e, f, i). A detailed characterization of uterine MCs revealed that they represent a heterogeneous population containing connective tissue MCs (Figure 1f ii), mucosal MCs (Figure 1f, iii) and MCs undergoing different stages of differentiation or transdifferentiation $^{28}$ (Figure 1f, iv). The uterine MC population was positive for CD117 (Figure 1f, v-vi) and mast cell protease 8 (Mcpt8; Figure 1f, vii-viii, and Supplementary Figure 2a),
}

while the percentage of uterine MCs expressing Mcpt5 oscillated between 5-20\%, as shown using isolated uterine cells from Mcpt5-Cre ROSA26 EYFP mice (C57BL/6J background; ${ }^{29}$ Supplementary Figure $\left.2 b\right)$. Thus, uterine MCs represent a heterogeneous population characterized by a distinctive phenotype.

$\mathrm{Kit}^{\mathrm{W}-\mathrm{sh} / \mathrm{W} \text {-sh }}$, c-Kit deficient mice, present a phenotype of aberrant implantation that can be completely reverted by systemic or local transfer of wild-type MCs. To analyze implantation, $K i t^{W-s h} / W$-sh females (C57BL/6J background) were mated with BALB/c males, because allogeneic matings represent natural, biologically relevant combinations compared with, for example, syngeneic ones. MC deficiency was related with significantly less implanted blastocysts compared with wild types (median $=0, n=23$ versus median $=$ 9, $n=19, P<0.05$; Table $1 \mathrm{a}$ and Figure 2a). Uteri from $K i t^{W-s h} / W$-sh mice were swollen and reddish with no implantations (Figure 2a iii), or contained few macroscopically normal implantations (Figure 2a iv). Implantation was also impaired in the context of a syngeneic combination (Supplementary Table 1) and litter size in $K i t^{W-s h / W-s h}$ mice was significantly reduced (Supplementary Table 2). Reconstitution of $K i t^{W-s h} / W$-sh mice with bone marrow-derived wild type and therefore c-Kit-expressing mast cells (BMMCs) completely restored the numbers of implantations and litter size (median: 7, $n=17$; Table 1 and Figure 2a, v). Systemic MC transfer successfully reconstituted the MC compartment in lymph nodes draining the fetal-maternal unit (Figure 2b), inguinal and mesenteric lymph nodes (Figures $2 \mathrm{c}$ and $\mathrm{d}$ ), and the decidua (Figure 2e). As the development of all hematopoietic stem cells is dependent on SCF, the $c$-Kit ligand, it would be possible that other immune cell populations could be affected by the defective $c$-Kit signaling in the $\mathrm{Kit}^{W-s h / W \text {-sh }}$ model. However, BMMC transfer did not lead to relevant changes in the frequency of T helper cells, NK cells, cytotoxic T cells or activated dendritic cells in spleen, lymph nodes, blood or decidua (data not shown), excluding the possibility that these immune cells could be responsible for the observed effects after reconstitution. This could be explained by the detected c-Kit expression in hematopoietic stem cells of $K i t^{W-s h} / W$-sh 16 Notably, uterine NKs were augmented in $K i t^{W-s h} / W$-sh animals compared with controls (data not shown), suggesting an interplay between these two cell types and a possible counterregulatory effect. Neutrophils were not analyzed.

As reconstitution with BMMCs normalized the peripheral and local MC compartment, we next examined whether uterine MCs are critical for implantation. We locally transferred BMMCs into one horn of the bicorneal uterus of $K i t^{W-s h} / W$-sh mice, whereas the other horn received buffer solution. Local transfer of MCs restored normal number of implantations at sites of MC transfer and augmented the expression of Mcpt1, Mcpt5 and Mcpt8 on mRNA levels (Supplementary Figure 3 and Supplementary Figures $4 a-c$ and Table 2). Although a significantly higher number of blastocysts were implanted in the MC-reconstituted uterine horn (Table 2), all females had at least one implantation on the mock-treated site (Supplementary Figures 3 and 5). This effect is most likely explained by the fact that these sites, which are directly adjacent to the MC-reconstituted uterus 

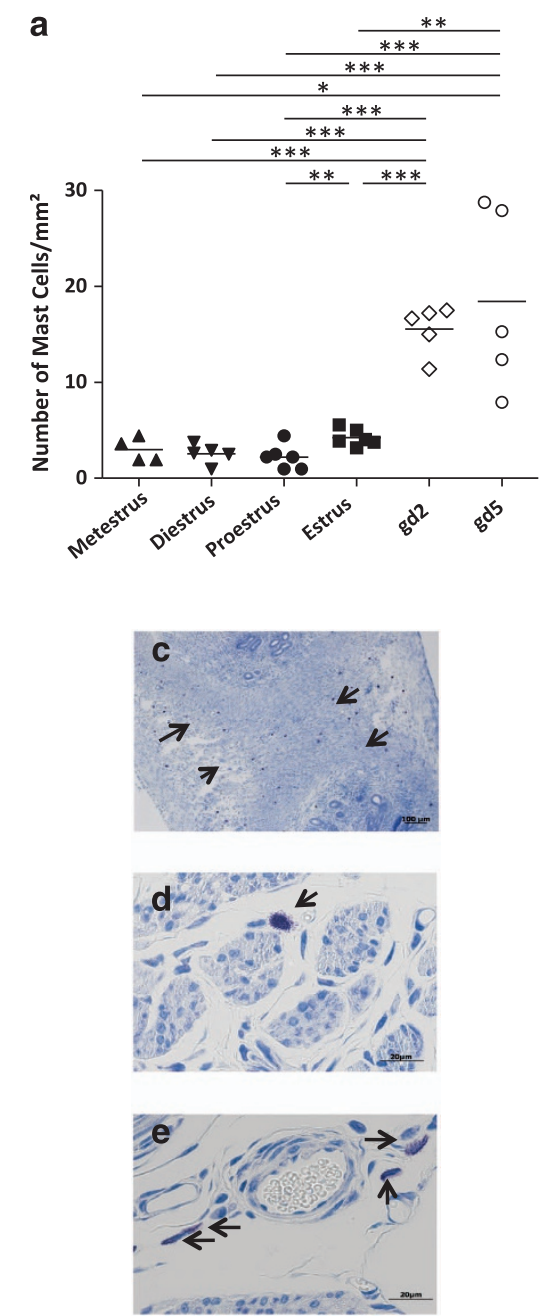

b

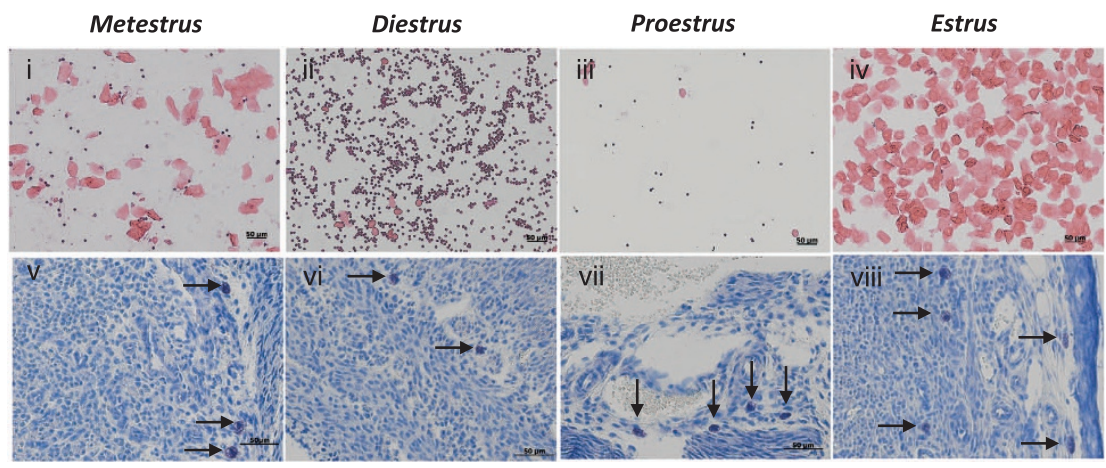

f

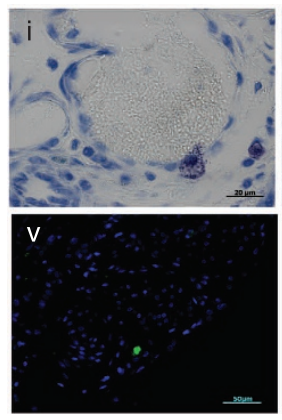

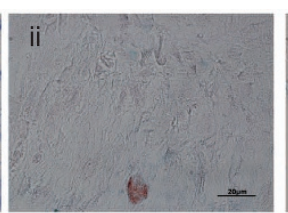

vi

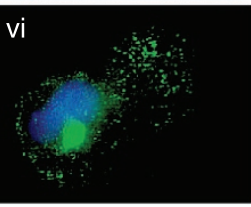

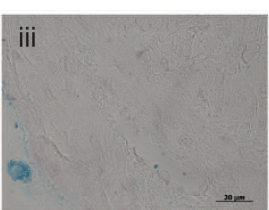
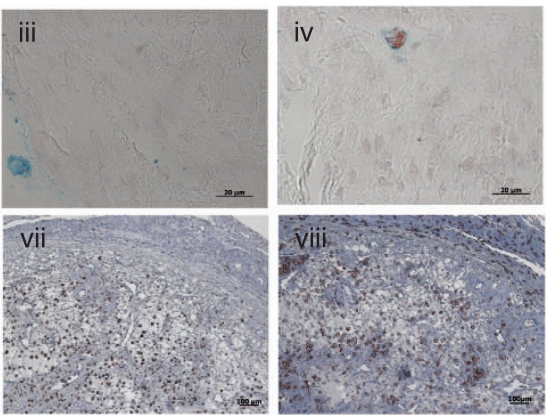

Figure 1 The numbers of uterine MCs increase during the fertile period of the estrus cycle and remain high during early gestation. Female virgin C57BL/6J females were checked for their phase of the estrous cycle. (bi-iv) Characteristic pictures from hematoxylin/eosin (H/E)-stained vaginal lavage samples of each phase are shown. (bv-viii) The number of MCs in uterine paraffin sections $(5 \mu \mathrm{m})$ of female virgin $(n=4-7)$, 2-day and 5 -day pregnant BALB/c-mated C57BL/6J females (gd2 and gd5, $n=5$ each) was quantified in $1 \mathrm{~mm}^{2}$ (magnification $\times 200$ ) areas by visualizing them with Toluidine blue $\mathrm{O}$ staining $(0.1 \%)$. The mean MC number from both the right and left uterine horn was calculated and included in (a). At day 5 of pregnancy, MCs were located in between the implantation sites (c), whereas at day 10 of pregnancy, MCs were detected in the decidua, the maternal part of the fetomaternal interface, of BALB/c-mated C57BL/6J females (d) and are particularly localized close to blood vessels (e; magnification $\times$ 1000). (f) Uterine MCs that are positive for Toluidine blue (i), Safranin (ii), Alcian blue (iii) and double positive for Safranin and Alcian blue (iv). In the lower panel, uterine MCs are shown that are positive for CD117 (v and vi) or Mcpt-8 (vii and viii). i-iv and vi: magnification $\times 1000$, v and vii: $\times 100$ magnification and viii: $\times 400$ magnification. Arrows indicate uterine MCs. Data are expressed as single dots with medians and were analyzed by using the Mann-Whitney $U$-test $\left({ }^{\star} P<0.05 ;{ }^{* *} P<0.01 ;{ }^{* * *} P<0.001\right.$ )

Table 1 Number of implantations per animal and percentage of pregnant mice after detection of a definite vaginal plug (C57BL/6, Kit ${ }^{W-s h / W-s h}+\mathrm{PBS}$ and $K i t^{W-s h} W$-sh reconstituted with BMMC) after allogeneic mating with BALB/c males (data of implantations/animals are given as median in parentheses)

\begin{tabular}{|c|c|c|c|}
\hline & $\begin{array}{l}\text { Implantations/ } \\
\text { animals } \\
\text { (mean; median) }\end{array}$ & $\begin{array}{c}\text { Pregnant/ } \\
\text { plugged } \\
(\%)\end{array}$ & $P$-value \\
\hline (a) C57BL/6J & $144 / 19(7.6 ; 9)$ & 84.2 & \\
\hline (b) $K i t^{W-s h / W-s h}+\mathrm{PBS}$ & $81 / 23(3.5 ; 0)$ & 47.8 & 0.02 to $(a)$ \\
\hline $\begin{array}{l}\text { (c) } K i t^{W-s h / W-s h}+\text { BMMCs } \\
\text { (systemically) }\end{array}$ & $113 / 17(6.6 ; 7)$ & 76.5 & 0.05 to $(b)$ \\
\hline
\end{tabular}

Statistical significances were calculated by Kruskall-Wallis test followed by Mann-Whitney $U$-test among two particular groups and are shown in the right column of the table horn, also showed MCs (Supplementary Figure 5b) indicating migration of MCs within the uterus or their clonal expansion. Our findings show that $K i t^{W-s h W-s h}$ mice present aberrant implantation that can be completely corrected upon systemic or local transfer with BMMCs. Hence, MCs are important players in implantation.

MC transfer into c-Kit-deficient mice promoted remodeling of spiral arteries: correlation with changes in Mcpts, TGF- $\boldsymbol{\beta 1}$ and CtGF. To gain insights into the mechanisms underlying MC modulatory activity, we further examined their effect on tissue remodeling that is manifested by the ability of blastocysts to implant. At day 5, implantations of different sizes could be observed (Supplementary Figure 6). Those

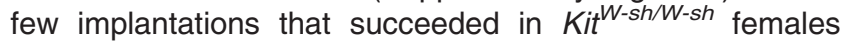


a i

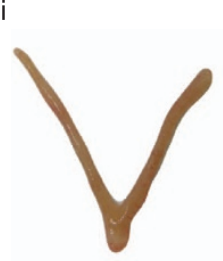

C57BL/6J

(virgin)

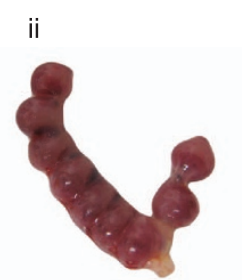

iii

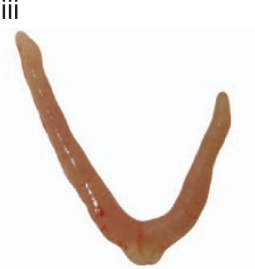

C57BL/6J W-sh with no implantations (gd 10) after successful mating (gd10)

iv

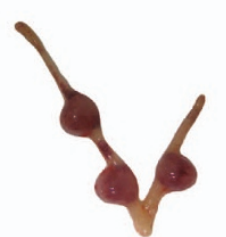

W-sh with three implantations after successful mating (gd 10)
V

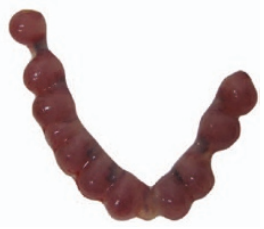

W-sh + syst BMMCs (gd 10)

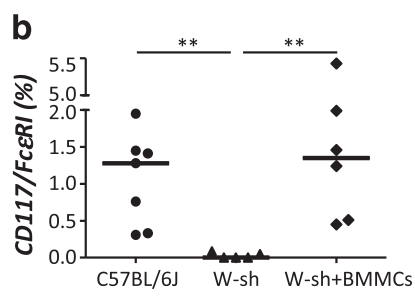

Para-aortic LN
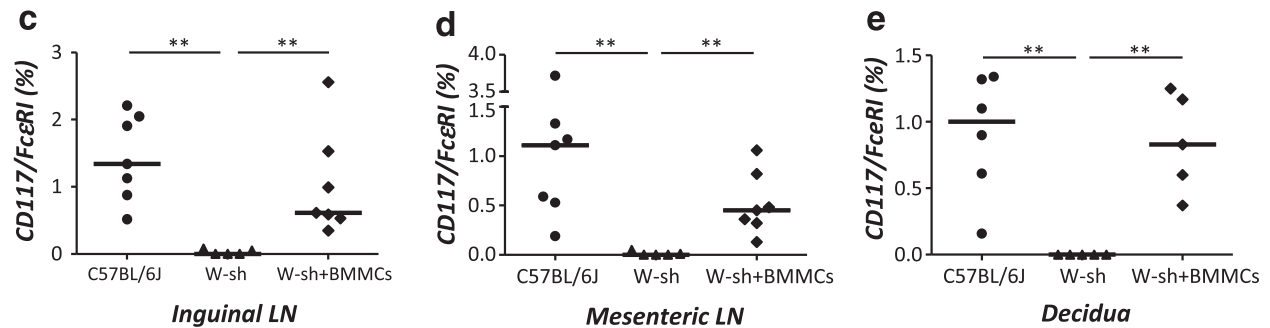

Figure 2 Systemic transfer of BMMCs reverses the low number of implantations of MC-deficient mice. Kit ${ }^{W-s h / W-s h}$ females (W-sh) were reconstituted systemically with BMMCs 12 weeks before being mated with BALB/c males. Implantation success was documented on day 10 of pregnancy. BALB/c-mated C57BL/6J females and Kit ${ }^{W-s h / W-s h}$ females served as controls. In (a) representative pictures are shown from uteri of (i) a virgin C57BL/6J female, (ii) a normal pregnant C57BL/6J, (iii) a non-pregnant Kit ${ }^{W-s h} / W$-sh female with an inflamed and thickened uterus after successful mating, (iv) a pregnant $K_{i t}{ }^{W-s h / W-s h}$ female presenting only three implantations and (v) a pregnant $K{ }^{W} t^{W-s h} / W$-sh female that was systemically reconstituted with BMMCs from wild-type mice showing 11 implantations. (b-d) Percentage of CD117/FceRl $\alpha^{+}$cells in para-aortic (b), inguinal (c) and mesenteric (d) lymph nodes from C57BL/6J $(n=7)$; Kit ${ }^{W-s h W-s h}(n=5)$ or Kit ${ }^{W-s h W-s h}+$ BMMCs $(n=6-7)$ animals. (e) Percentage of CD117/FcERl $\alpha^{+}$cells in the decidua from C57BL/6J $(n=6), K_{i t}{ }^{W-s h / W-s h}(n=5)$ and Kit ${ }^{W-s h W-s h}+$ BMMCs $(n=5)$ animals. Data are expressed as medians. ${ }^{*} P<0.05,{ }^{* *} P<0.005$, ${ }^{\star * \star} P<0.001$ as analyzed by Kruskall-Wallis test followed by Mann-Whitney Utest between two particular groups

Table 2 Number of implantations per animal in non-reconstituted (NR) and local reconstituted $(\mathrm{R})$ uterine horns in $K i t^{W \text {-sh } / W \text {-sh }}$ with BMMCs after allogeneic mating with BALB/c males

\begin{tabular}{lcc}
\hline & $\begin{array}{c}\text { Implantations/animals } \\
\text { (NR, median) }\end{array}$ & $\begin{array}{c}\text { Implantations/animals } \\
(\boldsymbol{R}, \text { median) }\end{array}$ \\
\hline $\mathrm{Kit}^{\mathrm{W} \text {-sh } / W \text {-sh }}$ & $18 / 10(1)$ & $37 / 10(4)^{*}$
\end{tabular}

${ }^{\star} P<0.05$ versus values for implantations/animal in the non-reconstituted uterine horn (data of implantations/animals are given as median in parentheses) analyzed by the Mann-Whitney $U$-test

were significantly smaller at day 5 , at which implantation should be finished (Figure 3a) and their development was significantly delayed (Figure $3 b$ ). Smaller implantations reflect defective nidation or even embryos that may not further develop ${ }^{30}$ and derive thus in less or no embryos at later pregnancy stages. BMMC transfer further resulted in significantly augmented size and timely development of implantations (Figures $3 c$ and d).

Successful implantation requires both tissue remodeling and angiogenesis. These processes involve the inducible expression of several mediators including VEGF-A, matrix metalloproteinase 9 (MMP-9), plasminogen activator inhibitor 1 (PAI-1), urokinase plasminogen activator (UPA), tissue-type plasminogen activator (tPA), TGF- $\beta 1$ and CtGF, many of them synthesized by MCs. ${ }^{31}$ We found that although mRNA levels for UPA, tPA, VEGF-A, MMP-9 and PAI-1 augmented following $M C$ transfer, this upregulated expression, however, did not account for the 'loss-of-function' phenotype as no significant differences could be observed between wild-type and MC-deficient animals (Supplementary Figures 7a-e). This might be alternatively due to a compensation process based on the augmented number of uNK cells, which synthesize all these factors.

$\mathrm{MC}$ chymases are known to be effector molecules of MCs that further activate other factors involved in tissue remodeling. ${ }^{32,33}$ mRNAs for Mcpts 1, 5 and 8, which were barely expressed in the decidua of $\mathrm{Kit}^{W \text {-sh/W-sh }} \mathrm{MC}$-deficient mice, were highly expressed following BMMC transfer (Supplementary Figures $8 \mathrm{a}-\mathrm{c}$ ). The mRNA expression of TGF- $\beta 1$ and connective tissue growth factor (CtGF), both proangiogenic molecules relevant for tissue remodeling, was significantly diminished at the fetal-maternal interface of c-Kit-deficient mice and BMMC transfer restored these cytokine levels (Figures $3 e$ and $\mathrm{f}$ ). TGF- $\beta 1$ was expressed by both MCs and trophoblasts (Figure $3 \mathrm{~g}$ ). In vitro, BMMCs secrete higher amounts of TGF- $\beta 1$ than placenta explants as measured by ELISA (data not shown). CtGF was exclusively produced by trophoblasts and MCs showed high expression of TGF- $\beta$ receptors (Figure $3 \mathrm{~g}$ ). This suggests a regulatory loop. Of note, positive correlations between TGF- $\beta 1$, CtGF and Mcpt8 were detected (Supplementary Figures $9 a-c$ ). Thus, MCs contribute to tissue remodeling that allows implantation and normalize the TGF- $\beta / \mathrm{CtGF}$ axis at the trophoblast/MC interface. Impaired implantations in c-Kitdeficient mice may result in improper placentation and fetal development. ${ }^{30}$ In fact, MC-deficient mice exhibited significantly smaller placentas at day 10 of pregnancy (Figure $4 a-c$, quantified in Figure 4d). A more in-depth examination 
a

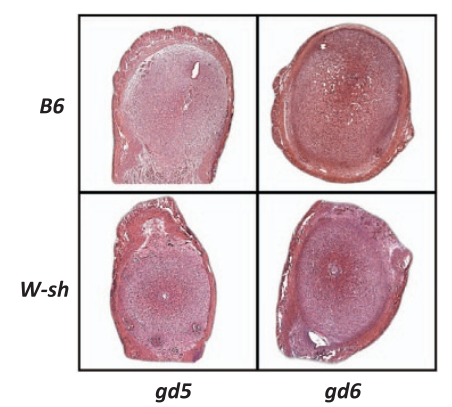

b

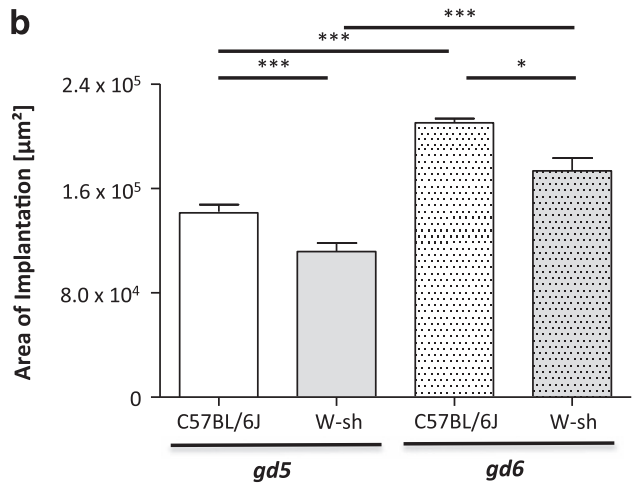

C

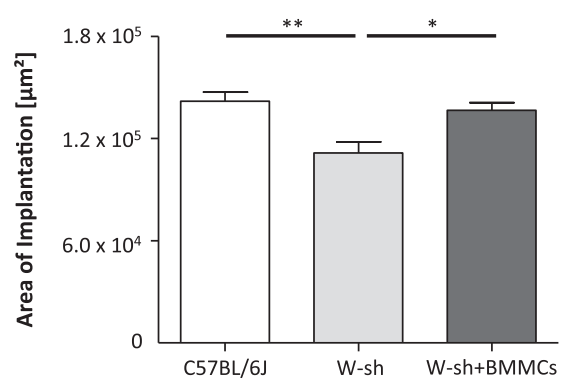

d

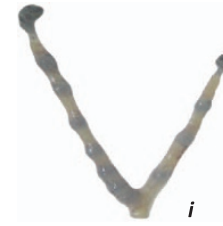

C57BL/6J
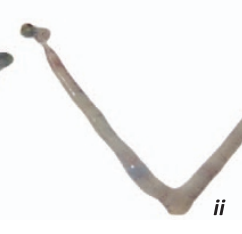

W-sh

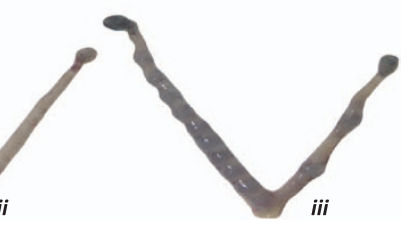

w-sh + BMMCs

e

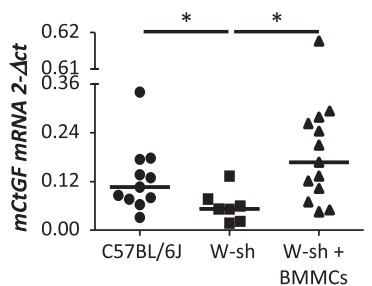

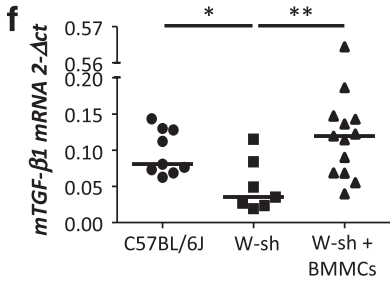

g

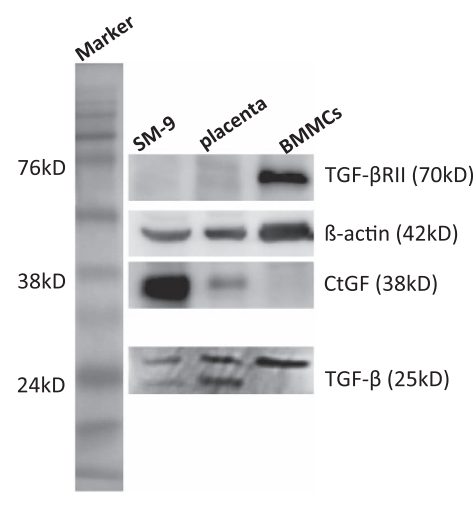

Figure 3 Implantation areas of $\mathrm{Kit}^{\mathrm{W}-\mathrm{sh} / \mathrm{W} \text {-sh }}$ (W-sh) females are significantly smaller than those of wild-type mice and this can be reversed by transfer of BMMCs; Normalization of the TGF- $\beta /$ CtGF axis. (a) Representative images of implantations as recorded at gestation days (gd) 5 and 6 in wild-type C57/BL6 and Kit ${ }^{W-s h} / W$-sh mice after Chicago Blue dye injection. The quantification of the area size $\left(\mu \mathrm{m}^{2}\right)$ was done by AxioVision4 (Zeiss) and is shown in (b) the number of mice per group was as follows: C57/BL6 day 5: $n=9$ and day 6: $n=4, K_{i t}{ }^{W-s h / W-s h}$ day 5: $n=6$ and day $6 n=4$. (c and d) representative uteri (c) and the measured implantation areas (d) at day 5 as

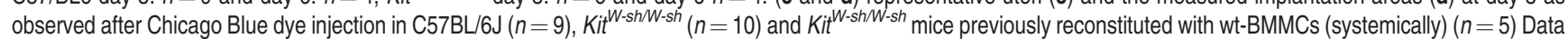
are expressed as means. Statistical significances were analyzed by unpaired $t$-test. ${ }^{*} P<0.05$, ${ }^{* *} P<0.005$, ${ }^{* * *} P<0.001$. Expression of CtGF (e) and TGF- $\beta 1$ (f) mRNA in decidual tissue of female C57BL/6J $(n=9-11)$, not reconstituted Kit ${ }^{\text {W-sh } / W \text {-sh }}(\mathrm{W}$-sh; $n=7)$ and systemically reconstituted Kit ${ }^{\mathrm{W}-\mathrm{sh} / \mathrm{W} \text {-sh }}(n=13)$ mice. BMMC reconstitution leads to upregulated expression of both genes to levels comparable to those observed in C57BL/6J mice. Data are expressed as median and statistical significances were analyzed by Kruskall-Wallis followed by Mann-Whitney U-test. ${ }^{*} P<0.05$ and ${ }^{* *} P<0.01$. (g) Expression of TGF- $\beta 1$, CtGF, TGF- $\beta$ RII and $\beta$-actin (served as house keeping gene) in murine trophoblast cells (SM9-2), trophoblast tissue from day 10 pregnant C57BL/6J female and wild-type BMMCs was analyzed by western blot

revealed that spiral arteries generated in the absence of MCs displayed reduced lumen diameter and a higher wall/lumen ratio compared with those of wild-type mice (Figures 4e-g; quantified in Figures $4 \mathrm{~h}$ and i). Reconstitution with BMMCs normalized both parameters (Figure $4 \mathrm{~h}$ and i) and resulted in increased placental surface area (Figure 4d). This observation was critical, as a narrow lumen implies a defective oxygen and nutrient transport to the fetus, which can have fatal consequences for placental and fetal development. Collectively, these data confirm that MCs normalize pregnancy in c-Kit-deficient mice by positively influencing spiral artery remodeling, placentation and, thus, fetal growth.

Galectin-1 is secreted by MCs and mediates their positive effects on placentation and fetal growth. To further understand the mechanisms underlying MC-associated normalization of placentation, we next focused our attention on galectin-1 (Gal-1) that has emerged as a regulator of pregnancy ${ }^{34}$ and is abundant in human and mouse reproductive tracts. ${ }^{35}$ Given the role of Gal-1 in trophoblast survival and syncytium formation, ${ }^{36}$ we asked whether MCs secrete Gal-1 to regulate placentation. Indeed, MCs expressed Gal-1 (Figures $5 \mathrm{a}$ and b). Interestingly, Lgals1 mRNA expression was reduced in decidual tissue of MC-deficient animals, which was restored following adoptive transfer of wild-type BMMCs ( $2^{-\Delta \text { ct. }} 23.3443$ in $K i t^{W-s h} / W$-sh mice versus $2^{-\Delta c t}$ : 36.6948 in wild-type mice and $2^{-\Delta c t}$. 55.5225 in reconstituted mice, $P<0.05)$. To examine the functional relevance of MC-derived Gal-1, we adoptively transferred $K i t^{W-s h / W-s h}$ mice with Gal-1-deficient (Lgals $1^{-/-}$) BMMCs. The majority of the implanted embryos did not survive until day 10 of pregnancy (Table 3a). Kit ${ }^{W-s h} / \mathrm{W}$-sh mice transferred with Lgals $1^{-/-}$BMMCs presented a median of $100 \%$ of fetal death compared with $18.2 \%$ observed in $K i t^{W-s h} / W$-sh mice transferred with wild-type BMMCs (Table $3 a$ and Figures $5 b$ and c). Placentas from surviving embryos were characterized by smaller labyrinth areas and unusual big areas of giant cells (GCs, Figure $5 d$ ). GCs showed abnormalities including several vacuoles in their cytoplasm (Supplementary Figure 10). In vivo, an incomplete reconstitution with $\mathrm{MCs}$ in the uterus and the draining lymph nodes was observed if Lgals1 $^{-/-}$BMMCs 
a

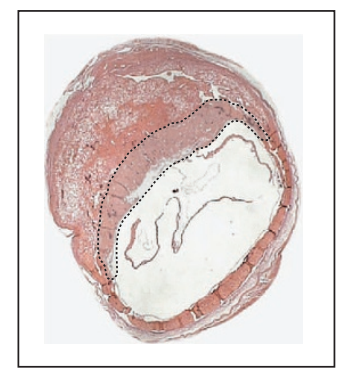

C57BL/6J b

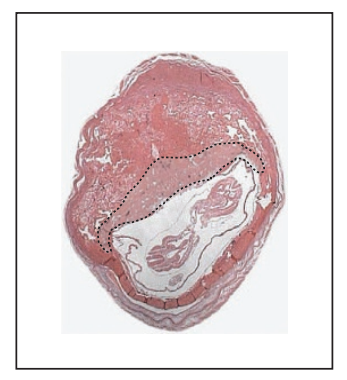

W-sh c

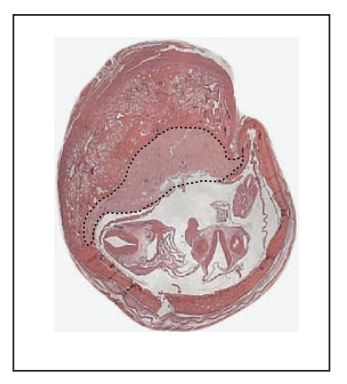

W-sh+BMMCs

g

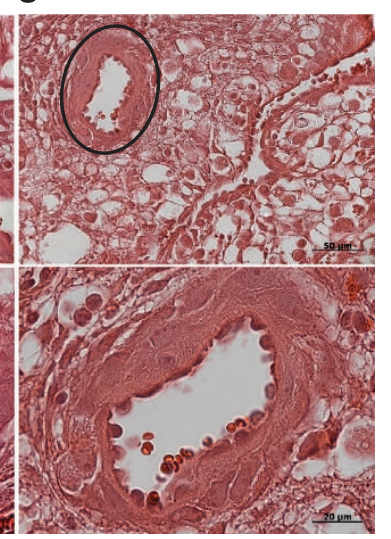

d
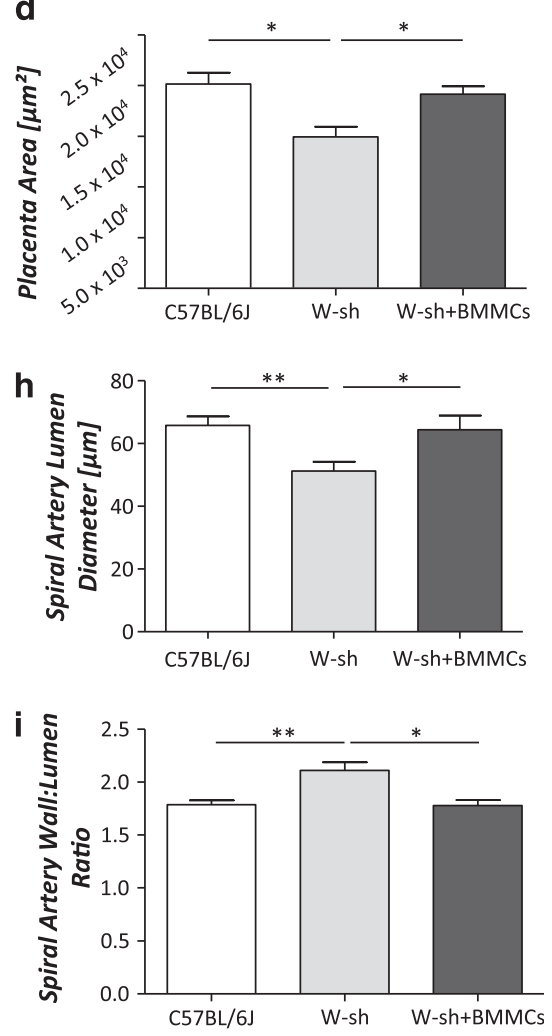

C57BL/6J

W-sh

w-sh+BMMCs

Figure 4 Mast cell deficiency results in suboptimal spiral artery remodeling and decreased placenta size: prevention by systemic BMMC transfer. Representative images

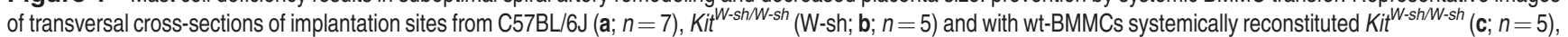
all pregnant at day 10. Here, the placental surface area was measured and is shown as area in $\mu \mathrm{m}^{2}$ (d). (e-g) Spiral arteries from C57BL/6J $(\mathbf{a} ; n=8), K i t^{W-s h} / W$-sh $(\mathbf{b} ; n=5)$ and systemically reconstituted $K \mathrm{~K}^{\mathrm{W} \text {-sh } W \text {-sh }}(\mathbf{c} ; n=5)$ of the decidua basalis in histological sections stained with $\mathrm{H} / \mathrm{E}$ and quantified by AxioVision4 (Zeiss). The lumen diameter (h) and wall thickness of 2-10 spiral arteries/female were measured, the wall/lumen ratio was calculated and the mean was included in panel (i). The absence of MCs leads to an impaired spiral artery formation together with a decreased placenta size that could be corrected by a systemic reconstitution with BMMCs. Data are expressed as means. Statistical significances were analyzed by unpaired $t$-test. ${ }^{*} P<0.05$ and ${ }^{* *} P<0.01$

were transferred (Supplementary Figure 11). In addition, Gal1 deficiency in MCs led to decreased expansion of these cells in the presence of trophoblast cells in vitro (Supplementary Figure 12). This strongly suggests a defective proliferation of MCs in the uterus and/or incomplete migration of MCs to the uterus if they lack Gal-1.

Lgals1 $^{-1-}$ mice presented shallow spiral artery remodeling and altered placentation that could be rescued by the transfer of wild-type MCs. Spiral arteries from Lgals $1^{-/}$females were characterized by increased wall/ lumen ratio (Supplementary Figure 13a), wall thickness (Supplementary Figure 13b) and lumen diameter (Supplementary Figure 13c), which pointed to abnormal vessel function. Lgals $1^{-/-}$mice had smaller implantation sizes at day 5 of pregnancy, which were comparable to those observed in $\mathrm{Kit}^{\mathrm{W} \text {-sh } W \text {-sh }}$ mice (Supplementary Figure 14). The importance of MCs secreting Gal-1 in supporting pregnancy and fetal growth was underlined by the fact that the adoptive transfer of BMMCs from wild-type animals into Lgals $1^{-/}$mice provoked a statistically significant reduction in the abortion rate from 18.8 to $0 \%(P=0.0014$; Table $3 b$ and Figure $5 \mathrm{e}$ ). Thus, MC-derived Gal-1 may serve to promote expansion of these cells in an autocrine or paracrine manner and to sustain trophoblast survival, placentation and successful pregnancy.

\section{Discussion}

Adoptive transfer experiments in $\mathrm{Kit}^{W-s h / W \text {-sh }}$ revealed central roles of MCs in implantation and fetal survival by mediating spiral artery formation and placentation, both critical events that ensure optimal fetal development.

MCs are present in the female reproductive tract, ${ }^{19,21,22}$ yet the function of these cells in reproductive biology is uncertain. In pregnant rats, $\mathrm{MC}$ degranulation has positive effects on cervical angiogenesis. ${ }^{20}$ Menzies et al. ${ }^{27}$ recently reported no role for these cells in labor in a syngeneic context. Yet, the involvement of these cells during early pregnancy and in a biologically relevant allogeneic context has not been studied. We found that a transient population of uterine MCs appears in cycles and as a unique population composed of connective tissue-type MCs, mucosal MCs and a transitional population that share features of both phenotypes. The number of uterine MCs peaks at the fertile phase of the estrous cycle and remaining high if pregnancy establishes. 
a

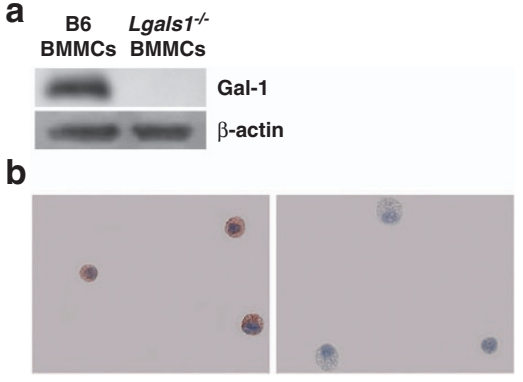

C

e
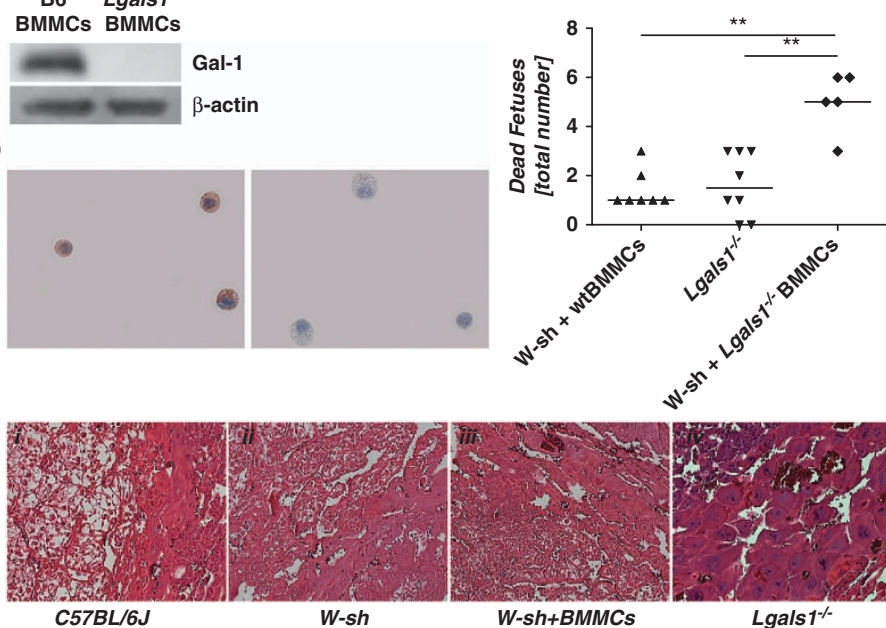

d

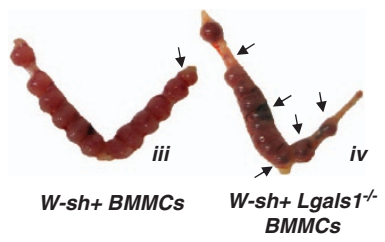

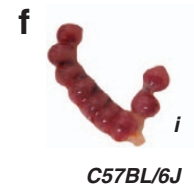
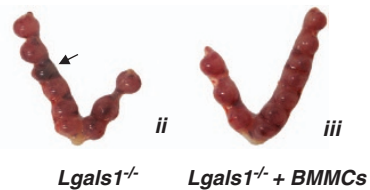

Figure 5 Critical role of Gal-1 in MC-dependent regulation of fetal death. (a and $\mathbf{b}$ ) Expression of Gal-1 at the protein level (western blot analysis as shown in a and immunohistochemistry ( $\times 1000$ magnification) as in $\mathbf{b}$ ) in BMMCs generated from virgin C57BL/6J females (wt-BMMC). BMMCs were additionally generated from virgin Lgals $1^{-1}$ females and injected systemically into Kit ${ }^{W-s h} / W$-sh females $(n=4)$. On day 10 of pregnancy, the number of dead fetuses was documented (arrows in d) and

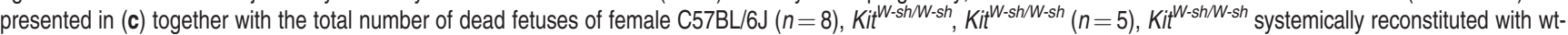
BMMC $(n=7)$ and Lgals $1^{-1}$ BMMC $(n=6)$ as well as Lgals $1^{-1-}(n=10)$. BMMCs express Gal-1 and the number of dead fetuses was significantly higher in KitW-sh/Wsh females receiving Lgals $1^{-1}$ BMMCs. Data are expressed as median and statistical significances were analyzed by Kruskall-Wallis followed by Mann-Whitney U-test. ${ }^{\star} P<0.05,{ }^{* \star} P<0.005$. (e) Representative images of the giant cell zone in histological, $\mathrm{H} / \mathrm{E}$ stained sections on day 10 of pregnancy are shown from C57BL/6J (i), Kit ${ }^{W-\text { sh } W \text {-sh }}$ (ii), Kit ${ }^{W-s h / W-s h}$ systemically reconstituted with wt-BMMC (iii), Lgals1 ${ }^{-1-}$ (iv) and Kit ${ }^{W-s h / W-s h}$ mice systemically reconstituted with Lgals $1^{-1-}$ BMMC (v) (magnification $\times 200$ ). The comparison between giant cells with a normal (vi) and an abnormal (vii) morphology is presented with $\times 400$ magnification. (f) Representative pictures of C57BL/

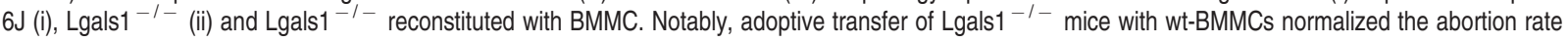

MCs are abundant in the uterus during early pregnancy. This appears to be regulated through endocrine mechanisms, which is not surprising as they express estrogen and progesterone receptors. ${ }^{37}$ We recently found that estradiol and progesterone promote MC migration from the periphery to the uterus. ${ }^{25}$ To investigate the role of MCs in pregnancy, we used C57BL/6J-Kit ${ }^{W-s h / W-s h}$ mice. Although MC deficiency in this particular model is caused by a defective $c$-Kit signaling that could further influence other signaling pathways, this model is well established and highly accepted. Although $K i t^{W-s h} / W$-sh mice were described as fertile, ${ }^{12}$ the maintenance of their colonies is difficult because of irregular birth rates and high natal and postnatal death rates. Allogeneically mated $K i t^{W-s h} / W$-sh mice show severely impaired implantation, although single mice may present normal litter size that account for their ability to breed. These single mice appear to carry their fetuses to term, an observation already made by Menzies et al. ${ }^{27}$ in a syngeneic context. The transfer of wildtype BMMCs could completely rescue the impaired reproductive phenotype. We demonstrate that MCs are present at the fetal-maternal interface after systemic and local reconstitution, suggesting that MCs act locally to foster normal pregnancy. Recently, c-Kit-independent models have been described, including a model that relies on the expression of Mcpt5 by MCs. ${ }^{38}$ Notably, we found that only $5-20 \%$ of uterine
MCs express Mcpt5, suggesting that $80 \%$ of MCs would not be depleted following diphtheria toxin administration. These results would also preclude using recently generated $\alpha$-chymase-Cre transgenic mice (Chm/Cre) whose Cre expression correlates to resident mucosal, but not to connective tissue-type MCs. ${ }^{39}$ In general, the generation of novel mouse models, whose MC deficiency is independent of a c-Kit-mutation, ${ }^{38,40}$ offer new insights in MC biology, but their relevance for different systems must be individually examined.

MC chymases Mcpt1, Mcpt5 and Mcpt8 were present at high levels in $K i t^{W-s h / W-s h}$ mice after systemic and local transfer. As chymases contribute to matrix degradation, tissue remodeling and angiogenesis, ${ }^{31}$ a new concept emerges, which implies MCs as essential initiators of tissue remodeling during pregnancy. We show that $M C$ deficiency results in severely impaired implantation followed by defective spiral artery remodeling, effects that are restored by $\mathrm{MC}$ reconstitution. Analysis of c-Kit-deficient uteri during implantation revealed blastocysts at different implantation stages. Measurement of the attached blastocysts revealed smaller sizes and a delayed kinetic than the wild types. These results are worthwhile to be discussed in terms of the fatal impact of delayed implantation in pregnancy outcome. ${ }^{30}$ Interestingly, reconstituted $K i t^{W-s h / W-s h}$ mice presented normal implantation 
Table 3a Number of implantations per females as well as mean and median of abortion rate after detection of a definite vaginal plug (C57BL/6, KitW-sh/W-sh + PBS, reconstituted $K i t^{W-s h} / W$-sh with BMMCs generated from C57BL/6J and reconstituted $K i t^{W-s h / W \text {-sh }}$ with BMMCs generated from $L g a l s 1^{-}{ }^{-}$) after allogeneic mating with BALB/c males on day 10 of pregnancy (data of implantations/females are given as mean and median in parentheses)

\begin{tabular}{|c|c|c|c|}
\hline & $\begin{array}{l}\text { Implantations/females } \\
\text { (mean; median) }\end{array}$ & $\begin{array}{l}\text { Mean; median of } \\
\text { fetal death [\%] }\end{array}$ & $P$-value \\
\hline (a) $C 57 B L / 6 J+P B S$ & $144 / 19(7.6 ; 9)$ & $5.4 ; 0$ & \\
\hline (b) $K i t^{W-s h / W-s h}+P B S$ & $81 / 24(3.4 ; 0)$ & $22.3 ; 4.1$ & 0.02 to $(a)$ \\
\hline (c) $K i t^{W-s h / W-s h}+C 57 B L / 6 J-B M M C$ & $59 / 9(6.6 ; 7)$ & $28.3 ; 18.2$ & $<0.005$ to $(b)$ \\
\hline (d) Lgals1-/- & $72 / 10(7.2 ; 9.5)$ & $26.1 ; 18.8$ & $<0.05$ to $(\mathrm{b})$ \\
\hline (e) $K i t^{W-s h / W-s h}+L g a l s 1^{-/-} B M M C$ & $35 / 6(5.8 ; 5.5)$ & $81.7 ; 100$ & $\begin{array}{l}<0.01 \text { to }(\mathrm{b}) \\
<0.05 \text { to }(\mathrm{c}, \mathrm{d}) \\
<0.005 \text { to }(\mathrm{a})\end{array}$ \\
\hline
\end{tabular}

Percentage of fetal death is expressed as mean and median. Statistical significances were calculated by Kruskall-Wallis test followed by Mann-Whitney $U$-test among two particular groups

Table 3b Number of implantations per females as well as mean and median of abortion rate after detection of a definite vaginal plug (C57BL/6, Lgals $1^{-1-}$ and Lgals $1^{-1-}$ reconstituted with BMMCs generated from C57BL/6J after allogeneic mating with BALB/c males on day 10 of pregnancy (data of implantations/females are given as mean and median in parentheses)

\begin{tabular}{llcl}
\hline & $\begin{array}{c}\text { Implantations/ } \\
\text { females (mean; } \\
\text { median) }\end{array}$ & $\begin{array}{c}\text { Mean; } \\
\text { median of } \\
\text { abortion } \\
\text { rate [\%] }\end{array}$ & P-value \\
\hline (a) C57BL/6J & $73 / 10(7.3 ; 9)$ & $7.6 ; 0$ & \\
(b) Lgals1 $1^{-1-}$ & $72 / 10(7.2 ; 9.5)$ & $26.1 ; 18.8$ & 0.06 to (a) \\
(c) Lgals1 $1^{-1-}$ & $68 / 11(6.2 ; 9)$ & $1.3 ; 0$ & 0.0014 to (b) \\
+C57BL/6J-BMMC & & & \\
\hline
\end{tabular}

Percentage of fetal death is expressed as mean and median. Statistical significances were calculated by Kruskall-Wallis test followed by MannWhitney $U$-test among two particular groups

numbers and sizes. This clearly shows that the aberrant implantation phenotype of c-Kit-deficient mice relies on the fact that they lack MCs.

The phenotype of $K i t^{W-s h / W-s h}$ mice may be attributable to the activation of $\mathrm{MC}$ proteases that stimulate other mediators involved in tissue remodeling and/or angiogenesis; these include tPA, UPA, PAI-1, VEGF-A, MMP9, tryptase and chymase. ${ }^{17,31,41,42}$ Systemic and local MC reconstitution of $K i t^{W-s h} / W$-sh mice led to increased uterine expression of several molecules, for example, UPA and tPA, both related to implantation. ${ }^{41}$ In line with this evidence, mice lacking UPA and tPA suffer from extensive fibrin deposition with impaired organ function, loss of fertility and reduced survival. ${ }^{43}$ PAl-1, known to have an essential role in tissue remodeling, ${ }^{44}$ was also augmented following $\mathrm{MC}$ reconstitution. Interestingly, PAl-deficient mice presented similar placental morphology like Lgals-1 $1^{-1-}$ mice. ${ }^{44}$ In this context, MC proteases may be more relevant as $\mathrm{C}-\mathrm{Kit}$-deficient mice have comparable PAI-1, uPA, tPA, VEGF-A and MMP-9 levels but significantly less Mcpts than wild types. We found that MCs are involved in the interplay between CtGF and TGF- $\beta 1$. CtGF has been implicated in matrix production during the menstrual cycle, uterine cell growth, ${ }^{45}$ implantation, development and differentiation of the embryo, ${ }^{46}$ extracellular matrix (ECM) synthesis and angiogenesis. ${ }^{47}$ TGF- $\beta 1$ mRNA was described in mouse tissues including placenta and developing mouse fetus. ${ }^{48}$ TGF- $\beta$-null mice develop a multiorgan autoimmune inflammatory disease leading to organ failure and rapid death after birth. ${ }^{49}$ In our system, trophoblasts and MCs were sources of TGF- $\beta 1$ whereas its receptor was highly expressed in MCs. We speculate that, as a consequence of a dysregulated TGF- $\beta 1 / \mathrm{CtGF}$ axis, thicker spiral artery walls are generated, leading to narrow lumen and inadequate fetus supply. In our model, these abnormalities were prevented upon reconstitution with wild-type BMMCs. Importantly, although lethality of mice lacking TGF- $\beta 1$ or CtGF precludes the possibility of analyzing the pathophysiologic relevance of these molecules in the context of MC deficiency, a strong positive correlation among MC-derived Mcpts, TGF- $\beta 1$ and CtGF could be confirmed.

The glycan-binding protein Gal-1 regulates multiple events associated with successful pregnancy, including trophoblast growth, syncytium formation and angiogenesis. ${ }^{35-37} \mathrm{We}$ confirmed here that MCs produce and secrete Gal-1. To the best of our knowledge, this is the first report implying MCs as a major source of Gal-1. Decidual tissue obtained from MCdeficient animals showed lower expression of Gal-1 that was restored after BMMC reconstitution. In vivo, adoptive transfer of $\mathrm{Kit}^{W-\mathrm{sh} / W \text {-sh }}$ animals with Lgals1 ${ }^{-/-}$BMMCs resulted in incomplete reconstitution of the uterus with MCs. Thus, Gal-1 is important for the expansion of MCs in the uterus as also suggested by our in vitro experiments or for their migration to the fetomaternal interface. Transfer of $L$ gals $1^{-1-}$ BMMCs resulted in higher number of fetal death as compared with mice reconstituted with wild-type BMMCs, confirming the critical role of Gal-1 secreted by MCs. Placentas from surviving embryos derived from $K{ }^{W}{ }^{W-s h} / W$-sh mice transferred with Lgals $^{-/-}$MCs showed altered placentation. Gal-1, secreted by MCs, substantially contributed to placentation and pregnancy success. Similar to $K i t^{W-s h} / W$-sh mice, spiral arteries from $L$ gals $1^{-1-}$ mothers were insufficiently remodeled, supporting the critical role of Gal-1 as a mediator of MC protective function. This was confirmed by experiments in which pregnant $L$ gals $1^{-1-}$ mice were transferred with Gal-1expressing BMMC, which completely abrogated fetal death. Our data clearly show that Gal- 1 secreted by MCs contributes to normal placentation through nonimmunological mechanisms.

Our data demonstrate that MCs play central roles in pregnancy by allowing tissue remodeling during implantation 
and/or by positively influencing placentation and fetal growth. These findings may help to delineate cellular mechanisms that govern successful pregnancies with potential applications to other biomedical fields.

\section{Materials and Methods}

Animals. To investigate the possible role of MCs in vivo in mouse pregnancy, we used MC-deficient C57BL/6J-Kit ${ }^{W-s h W \text {-sh }}$ mice. W-sash $\left(W^{\text {sh }}\right)$ is an inversion mutation in the transcriptional regulatory elements upstream of the $c$-kit transcription start site on mouse chromosome $5 .{ }^{13} \mathrm{~W}^{\text {sh }}$ mutation results in very few developmental abnormalities, and until very recently the only reported phenotypic abnormalities in $\mathrm{Kit}^{\mathrm{W} \text {-sh } W \text {-sh }}$ mice were an impairment of skin pigmentation and a MC deficiency in the skin and peritoneal cavity. ${ }^{50}$ However, $\mathrm{MC}$ deficiency after the age of 10 weeks becomes more profound with abnormalities reported in multiple anatomical sites. ${ }^{50}$ In all the experiments reported here, we used animals older than 10 weeks to assure MC deficiency.

The present study was authorized by the German Ministry and carried out according to institutional guidelines of Berlin and Magdeburg (LaGeSo, Berlin, Germany, Reg. no. 0070/03; 203.h-42502-2-868 Magdeburg) and the Guide for the Care and Use of Agricultural Animals in Agricultural Research and Teaching, USA. $B A L B / c$ male mice were purchased from Charles River (Sulzfeld, Germany). C57BL/6J-Kit ${ }^{W-s h / W-s h}$ MC-deficient females were obtained from Jackson Laboratories (Bar Harbor, ME, USA). Wild-type counterparts C57BL/6J were purchased from Charles River. Lgals $1^{-1-}$ mice were provided by Dr. F Poirier (Jacques Monod Institute, Paris, France) and bred at the Animal Facilities of the Medical Faculty, Otto-von-Guericke University (Magdeburg, Germany). Animals were maintained in our barrier animal facility with a 12-h light/dark cycle. All females were checked daily for vaginal plugs. The day at which the vaginal plug was detected was considered as day 0 of pregnancy and the females were separated from the males. The BALB/c-mated Kit ${ }^{W-s h / W-s h}, \mathrm{BL} / 6$ and $L$ gals $1^{-1-}$ BMMCreconstituted $\mathrm{Kit}^{\mathrm{W} \text {-sh/W-sh }}$, Lgals $1^{-1-}$ and control C57BL/6J females were killed on days 5,6 or 10 of pregnancy or for the local reconstitution between days 10 and 12 of pregnancy, and the uteri were removed and the implantation sites were documented.

The determination of the estrous cycle in virgin C57/BL6 females was performed by vaginal lavage with $0.9 \%$ sodium chloride. The stage of the cycle was defined based on the typical cell content of the lavage. Females were killed when they showed a clear stage. To confirm the stage, samples were stained with hematoxylin/ eosin and analyzed under light microscopy. The state of the cycle was defined based on the characteristic cell content in the fresh lavage (Axiovert 40C, Carl Zeiss, Jena, Germany; magnification $\times 200$ ) and stained (Axio Observer.A1, Carl Zeiss; magnification $\times 200$ ).

Isolation, culture and adoptive transfer of BMMCs. Bone marrow cells were collected from femurs and tibias of wild-type C57BL/6J or Lgals $1^{-1-}$ females and cultured in IMDM (Iscove's modified Dulbecco's medium) supplemented with $10 \%$ fetal bovine serum (FBS), 1\% penicillin/streptomycin and $30 \mathrm{ng} / \mathrm{ml}$ murine recombinant IL-3 (final, Invitrogen, Carlsbad, CA, USA) or $10 \mathrm{ng} / \mathrm{ml} \mathrm{WEHI-3-derived} \mathrm{IL-3} \mathrm{for} \mathrm{at} \mathrm{least} 5$ weeks, at which time $>95 \%$ of the cells were identified as BMMCs by flow cytometric analysis of $\mathrm{CD} 117^{+} \mathrm{Fc \varepsilon Rl} \alpha^{+}$ cells (Supplementary Figure 15).

For systemic MC reconstitution studies, BMMCs were transferred into 10-weekold Kit ${ }^{W-s h / W-s h}$ females by i.v. injection of $5 \times 10^{6}$ cells in $200 \mu$ l of PBS in the morning of two consecutive days (in total $1 \times 10^{7}$ cells) through the tail vein. For local reconstitution, $1 \times 10^{6} \mathrm{BMMCs}$ were injected into different sections of the right uterine horn of $K i t^{W-s h} / \mathrm{W}$-sh females, whereas the left uterine horn served as control and was mock-treated. At 12 weeks after systemic and 5 weeks after local transfer (reported time required for biological and physiological reconstitution), BMMCreconstituted $K \mathrm{Ki}^{\mathrm{W} \text {-sh } W \text {-sh }}$ females were allogenically mated with BALB/c males. Simultaneously, age-matched MC-deficient Kit ${ }^{W-s h} /$-sh and control C57BL/6J females were mated with $B A L B / c$ males.

Sample collection. On day 10 of pregnancy, one implantation site per female was collected for cryosections and one implantation site was collected for paraffin studies with previous fixation in $4 \%$ (w/v) PFA with $0.1 \mathrm{M}$ sucrose $(\mathrm{pH} 7.4)$ for $6 \mathrm{~h}$. The uterine horns were opened longitudinally and the fetal-placental unit carefully separated from the decidua. For flow cytometry analysis, decidual samples were cut in small pieces and collected in Hanks' balanced salt solution containing no $\mathrm{Ca}^{2+}$ or $\mathrm{Mg}^{2+}$ (Sigma, Taufkirchen, Germany). For RNA isolation or cell extract preparation for western blot analysis, tissues from placenta, decidua, spleen, thymus and lymph nodes (inguinal, axillary, mesenteric and iliac) were carefully washed with cold sterile PBS, pH 7.40 , snap-frozen, and kept at $-80^{\circ} \mathrm{C}$ until use. When analyzing uteri from day 5 or 6 of pregnancy, females were injected i.v. with Chicago Blue dye a few minutes before killing the animal, and uterine horns were dissected and fixed in $96 \%$ (v/v) ethanol.

Flow cytometry. Tissues from decidua, spleen, thymus and lymph nodes (inguinal, axillary, mesenteric and iliac) were processed as described ${ }^{51}$ and stained with the following antibodies: FITC-conjugated anti-mouse Fc $\varepsilon \mathrm{Rl} \alpha, \mathrm{PE}$ conjugated anti-mouse CD117, PE-conjugated rat anti-mouse I-A/I-E (MHCII), PerCP-Cy5.5-conjugated rat anti-mouse CD4, PE-Cy5-conjugated rat anti-mouse CD8a, APC-conjugated hamster anti-mouse CD11c, FITC-conjugated hamster anti-rat CD49b (which also reacts with mouse CD49b), FITC-conjugated Mcpt8 and Alexa Fluor 647-conjugated anti-mouse Foxp3. All antibodies were purchased from Becton Dickinson (BD, Heidelberg, Germany). The Fc\&Rl $\alpha$ antibody was from eBioscience (Kranenburg, Germany). For Mcpt8 staining a Biolegend (Fell, Germany) antibody was combined with a FITC-conjugated goat anti-rat, cells were permeabilized and the first antibody was incubated for $30 \mathrm{~min}$, followed by $30 \mathrm{~min}$ of the second antibody. For all analyses, the percentage of positive cells was referred to the leukocytes, unless otherwise stated. Cells stained with isotype controls (all from BD) as well as unstained cells served as controls.

Real-time reverse transcriptase-PCR (RT-qPCR). For real-time quantitative RT-PCR, total RNA was isolated from decidua, placenta and lymph nodes (inguinal, axillary, mesenteric, iliac). The tissue was treated with Trizol (Gibco, Life Technologies, Darmstadt, Germany) and disaggregated using a homogenator (Ultra Turrax T8; Ika, Staufen, Germany). The RNA was extracted with chloroform, precipitated with absolute ethanol, washed, and finally diluted in RNase-free water. The quantity and quality of the RNA was determined by ultraviolet absorbance at $260 \mathrm{~nm}$. Total RNA $(2 \mu \mathrm{g})$ was initially incubated with oligo dTs (Amersham Pharmacia, Freiburg, Germany) for 10 min at $75^{\circ} \mathrm{C}$ followed by $5 \mathrm{~min}$ of incubation on ice. Subtracted mRNA was then incubated with dNTPs ( $2.5 \mathrm{mmol} /$; Amersham Pharmacia), DNase I ( $2 \mathrm{U} / \mathrm{ml}$, Stratagene, Waldbronn, Germany) and RNase inhibitor ( $40 \mathrm{U} / \mathrm{ml}$, Promega, Mannheim, Germany) in a reaction buffer. The mix was incubated for $30 \mathrm{~min}$ at $37^{\circ} \mathrm{C}$ and further heated at $75^{\circ} \mathrm{C}$ for $5 \mathrm{~min}$. The addition of the RT (200 U/ml, Promega) and RNase inhibitor in diethyl pyrocarbonate water (diethyl pyrocarbonate was from Sigma) started the reverse transcription. This reaction mixture was incubated at $42^{\circ} \mathrm{C}$ for $60 \mathrm{~min}$, followed by incubation at $94^{\circ} \mathrm{C}$ for $5 \mathrm{~min}$. Amplification reactions were performed in $13 \mu \mathrm{l}$ of final reaction volume of SYBR Green Master Mix (Applied Biosystems, Darmstadt, Germany) as follows: initial denaturation at $95^{\circ} \mathrm{C}$ for $5 \mathrm{~min}$, followed by 40 cycles of denaturation step at $95^{\circ} \mathrm{C}$ for $45 \mathrm{~s}$ and annealing step at either $56^{\circ} \mathrm{C}$ or $60^{\circ} \mathrm{C}$ for $60 \mathrm{~s}$. All samples were normalized to the $\beta$-actin transcript levels. All reactions were carried out on an iCycler (Bio-Rad, Munich, Germany). Primer sequences are available upon request.

Western blot analysis. Protein extraction from tissue and cells was performed on ice. Tissue or cells were incubated in lysis buffer (10\% NP-40, $0.1 \mathrm{mg} / \mathrm{ml}$ n-Dodecil- $\beta$-D-maltoside, $500 \mathrm{~mm}$ sodium fluoride, $10 \mathrm{~mm}$ sodium metavanadate, $100 \mathrm{mM}$ PMSF, $1 \mathrm{M}$ Tris, $0.5 \mathrm{M}$ EDTA and $5 \mathrm{M} \mathrm{NaCl}$ ) for $60 \mathrm{~min}$. After sonication, cells were centrifuged and supernatants were collected. After overnight storage at $-80^{\circ} \mathrm{C}$, protein content was determined by Bradford assay (Bio-Rad) as indicated by the manufacturers. Then, $50 \mu \mathrm{g}$ of proteins were resolved on a $15 \%$ SDS-PAGE at $80 \mathrm{~V}$ for $4 \mathrm{~h}$ and transferred onto a $0.2 \mu \mathrm{m}$ nitrocellulose membrane in transfer buffer containing $20 \%(\mathrm{v} / \mathrm{v})$ methanol, $0.19 \mathrm{M}$ glycine and $0.025 \mathrm{M}$ Tris $(\mathrm{pH} 8.3)$ at a constant voltage $(80 \mathrm{~V})$ for $2 \mathrm{~h}$ on ice. After blocking nonspecific-binding sites with $5 \%(\mathrm{w} / \mathrm{v})$ skim milk powder in TBS with $0.05 \%(\mathrm{v} / \mathrm{v})$ Tween for $1 \mathrm{~h}$, blots were incubated overnight at $4{ }^{\circ} \mathrm{C}$ using the following antibodies: TGF- $\beta 1$ (V, $1: 200$, Santa Cruz, Heidelberg, Germany), CtGF (L-20, $1: 100$, Santa Cruz), TGF- $\beta$ RII (C-16, $1: 200$, Santa Cruz), Gal-1 $(1: 400)$ (kindly provided by Dr. GA Rabinovich, Ref. 61) and for $2 \mathrm{~h}$ at room temperature using $\beta$-actin (AC-15, 1: 10000 , Sigma-Aldrich, St. Louis, MO, USA), respectively.

Histopathology and immunohistochemistry. Uteri and whole implantation sites were dissected and fixed in either $96 \%$ (v/v) ethanol or 4\% (v/v) PFA with $0.1 \mathrm{M}$ sucrose, $\mathrm{pH}$ 7.4. After dehydration in ethanol, tissue samples were embedded in paraffin. Sections of $5 \mu \mathrm{m}$ thickness were stained with hematoxylin/ eosin for analysis of morphology and Toluidine blue dye $(0.1 \%$ aqueous solution or 
$0.5 \%$ in $0.5 \mathrm{~N} 5 \mathrm{~N} \mathrm{HCl}$ overnight) for visualizing MCs in the myometrium by the metachromatic staining of secretory granules. The number of MCs was analyzed within the myometrium and calculated per $1 \mathrm{~mm}^{2}$ by using an Eyepiecemicrometer (Zeiss). To distinguish between mucosal and connective tissue-type MCs, the uterine tissue was stained first with Alcian blue (1\% in 3\% acetic acid) followed by Safranin $(0.5 \%$ in $0.125 \mathrm{~N} \mathrm{HCl})$. For Mcpt8 staining, slides were boiled in citrate buffer and endogenous peroxidase and protein were blocked. The slides were incubated $\mathrm{ON}$ at $4{ }^{\circ} \mathrm{C}$ with anti-Mcpt8 (BioLegend) antibody followed by incubation with the secondary antibody goat anti-rat (Jackson Immuno Research, West Grove, PA, USA) for $1 \mathrm{~h}$ at RT. Counterstaining was done using hematoxylin.

DBA lectin reacts specifically with uterine NKs on all gestational days and at all stages of differentiation. To identify and quantify the number of uterine NKs, the DBA-lectin staining was done as described elsewhere. ${ }^{52}$ Tissue samples for cryosections (whole implantation sites) were embedded in cryo-medium and cut into $5 \mu \mathrm{m}$ sections. After air-drying, sections were stained with Toluidine blue dye $(0.5 \%$ in $0.5 \mathrm{~N} \mathrm{HCl}$ ) for identification of MCs. Immunofluorescence for CD117 was performed using a primary antibody from Cedarlane Lab (Burlington, ON, Canada) and FITC-labeled goat anti-rat (Invitrogen) as secondary antibody.

Quantitative histological measurements. The quantitative measurements of the implantation sites as well as placentas were done as described elsewhere ${ }^{52}$ by using the software AxioVision4 (Zeiss). Shortly, H/E-stained sections were used to measure the surface area of both the implantation sites on gestation days 5 and 6 as well as the size of the placenta (both in $\mu \mathrm{m}^{2}$ ) at a $\times 200$ magnification. To best characterize the size of the placenta at day 10 , we cut 10 serial sections from the central part of each implantation site. This section, which contains the largest placental area, was chosen for the analysis. Then, upon having this clearly defined area we proceeded to determine the surface area as described in Croy et al..$^{52}$ This method allows the best possible characterization of the placenta size due to the technical impossibility of dissecting this tissue from the rest at day 10 of pregnancy. The quantitative measurements of the spiral arteries was performed as described elsewhere ${ }^{52}$ Briefly, the spiral artery wall and lumen diameters were measured by using the software AxioVision (Zeiss) and/or expressed as wall/lumen ratios and wall thickness.

Co-culture experiments. The murine trophoblast cell line SM9-2 was propagated in culture in RPMI-1640 with $20 \% \mathrm{FBS}$ and $1 \%$ penicillin/streptomycin, $1 \mathrm{mM}$ sodium pyruvate, $5 \times 10^{-5} \mathrm{M}$ 2-mercapthoethanol, incubated at $37^{\circ} \mathrm{C}$ in a humidified atmosphere of $5 \% \mathrm{CO}_{2}$. PKH26-stained SM9-2 cells were co-cultured with CFDA-SE-stained BMMCs for $48 \mathrm{~h}$ and the proliferation of trophoblasts was measured using flow cytometry.

Data analysis and statistics. Data were analyzed using GraphPad Prism5 (Witzenhausen, Germany), expressed as means or medians depending on their distribution (normal or not normal). For data regarding MC quantification, flow cytometry, PCR and in vivo data after BMMC reconstitution, differences among all groups were calculated by the Kruskall-Wallis test and the difference between two independent groups was calculated using the Mann-Whitney U-test. To analyze differences in the implantation numbers in the half of the uterus transferred with BMMCs or with vehicle, the Wilcoxon test was applied. For histological analysis of implantation size at day 5 as well as histological measurements, 1 to 6 implantations and 2 to 10 spiral arteries per female were measured by AxioVision4 (Zeiss), the mean for each specimen was calculated, and the differences between the animal groups analyzed using unpaired $t$-test. For all tests, $P$-value of $<0.05$ was considered to be statistically significant. The number of samples or animals, the statistical test used and the $P$-values obtained are indicated in each figure or table legend.

\section{Conflict of Interest}

The authors declare no conflict of interest.

Acknowledgements. We thank Sina Heydrich and Markus Scharm for their excellent technical assistance and Jodie Urcioli for proof reading of the manuscript. We are very thankful to Axel Roers who kindly provided the C57BL/6J-Mcpt5-Cre ROSA26 EYFP mice. We also thank Joan Hunt for providing the SM9-2 trophoblast cell line and Siegfried Kropf for his expert advice in Statistics. This work was mainly supported by grants to ACZ (Deutsche Forschungsgemeinschaft ZE 526/7-1 and Fritz Thyssen Foundation 10.08.2.179) and M Maurer (DFG SPP1394). GAR is supported by the Argentinean Agency for Promotion of Science and Technology, University of Buenos Aires, Mizutani Foundation for Glycoscience, National Council for Scientific and Technical Investigations and Fundación Sales. FP thanks Groupements des Entreprises Francaises dans la Lutte contre le Cancer, Ligue Comite de Paris and Association Recherche contre le Cancer no. 1746. ACZ, KW, FJ and M Metz are members of the DFG Priority Programme 1394 (MCs as regulators of health and disease). M Maurer is a member and coordinator of the DFG Priority Programme 1394 (MCs as regulators of health and disease). ACZ, FJ, M Metz and M Maurer are members of the COST action BM1007: Mast cells and Basophils, targets for innovative therapies.

\section{Author Contributions}

KW and MP designed and performed experiments, analyzed data and contributed to manuscript preparation. M Metz performed experiments and analyzed data. AS, NL and AT performed experiments. FP and SF contributed with reagents and to manuscript preparation. FJ designed and performed experiments and analyzed data. GAR analyzed data and substantially contributed to manuscript preparation. M Maurer designed and performed experiments, analyzed data and substantially contributed to manuscript preparation. ACZ supervised the work, designed experiments, analyzed data and wrote the paper.

1. Ogawa M, Matsuzaki Y, Nishikawa S, Hayashi S, Kunisada T, Sudo T et al. Expression and function of c-kit in hemopoietic progenitor cells. J Exp Med 1991; 174: 63-71.

2. Dastych J, Metcalfe DD. Stem cell factor induces mast cell adhesion to fibronectin. $J$ Immunol 1994; 152: 213-219.

3. Ohta H, Yomogida K, Dohmae K, Nishimune $\mathrm{Y}$. Regulation of proliferation and differentiation in spermatogonial stem cells: the role of $c-k i t$ and its ligand SCF. Development 2000; 127: 2125-2131.

4. Hutt KJ, McLaughlin EA, Holland MK. KIT/KIT ligand in mammalian oogenesis and folliculogenesis: roles in rabbit and murine ovarian follicle activation and oocyte growth. Biol Reprod 2006; 75: 421-433.

5. Moore PA, Belvedere O, Orr A, Pieri K, LaFleur DW, Feng P et al. BLyS: member of the tumor necrosis factor family and B lymphocyte stimulator. Science 1999; 285: 260-263.

6. Kehrl JH, Wakefield LM, Roberts AB, Jakowlew S, Alvarez-Mon M, Derynck R et al. Production of transforming growth factor beta by human $\mathrm{T}$ lymphocytes and its potential role in the regulation of T cell growth. J Exp Med 1986; 163: 1037-1050.

7. Besmer P. The kit ligand encoded at the murine Steel locus: a pleiotropic growth and differentiation factor. Curr Opin Cell Biol 1991; 3: 939-946.

8. Sharkey AM, Jokhi PP, King A, Loke YW, Brown KD, Smith SK. Expression of c-kit and kit ligand at the human maternofetal interface. Cytokine 1994; 6: 195-205.

9. Horie K, Fujita J, Takakura K, Kanzaki H, Kaneko Y, Iwai M et al. Expression of c-kit protein during placental development. Biol Reprod 1992; 47: 614-620.

10. Nocka K, Tan JC, Chiu E, Chu TY, Ray P, Traktman P et al. Molecular bases of dominant negative and loss of function mutations at the murine c-kit/white spotting locus: W37, Wv, W41 and W. EMBO J 1990; 9: 1805-1813.

11. Russel ES, Bernstein SE. Blood and blood formation. In Green EL (ed). Biology of the Laboratory Mouse. Mc-Graw-Hill: New York, pp 351-372.

12. Lyon MF, Glenister PH. A new allele sash (Wsh) at the W-locus and a spontaneous recessive lethal in mice. Genet Res 1982; 39: 315-322.

13. Nagle DL, Kozak CA, Mano H, Chapman VM, Bućan M. Physical mapping of the Tec and Gabrb1 loci reveals that the Wsh mutation on mouse chromosome 5 is associated with an inversion. Hum Mol Genet 1995; 4: 2073-2079.

14. Wolters PJ, Mallen-St Clair J, Lewis CC, Villalta SA, Baluk P, Erle DJ et al. Tissue-selective mast cell reconstitution and differential lung gene expression in mast cell-deficient Kit (W-sh)/Kit(W-sh) sash mice. Clin Exp Allergy 2005; 35: 82-88.

15. Grimbaldeston MA, Chen CC, Piliponsky AM, Tsai M, Tam SY, Galli SJ. Mast cell-deficient W-sash c-kit mutant Kit W-sh/W-sh mice as a model for investigating mast cell biology in vivo. Am J Pathol 2005; 167: 835-848.

16. Berrozpe G, Timokhina I, Yukl S, Tajima Y, Ono M, Zelenetz AD et al. The W(sh), W(57), and $\mathrm{Ph}$ Kit expression mutations define tissue-specific control elements located between -23 and -154 kb upstream of Kit. Blood 1999; 94: 2658-2666.

17. Galli SJ, Nakae S, Tsai M. Mast cells in the development of adaptive immune responses. Nat Immunol 2005; 6: 135-142.

18. Horie K, Fujita J, Takakura K, Kanzaki H, Suginami H, Iwai M et al. The expression of c-kit protein in human adult and fetal tissues. Hum Reprod 1993; 8: 1955-1962.

19. Mori A, Zhai YL, Toki T, Nikaido T, Fujii S. Distribution and heterogeneity of mast cells in the human uterus. Hum Reprod 1997; 12: 368-372.

20. Varayoud J, Ramos JG, Bosquiazzo VL, Muñoz-de-Toro M, Luque EH. Mast cells degranulation affects angiogenesis in the rat uterine cervix during pregnancy. Reproduction 2004; 127: 379-387.

21. Bosquiazzo VL, Ramos JG, Varayoud J, Muñoz-de-Toro M, Luque EH. Mast cell degranulation in rat uterine cervix during pregnancy correlates with expression of vascular endothelial growth factor mRNA and angiogenesis. Reproduction 2007; 133: 1045-1055. 
22. Bytautiene E, Vedernikov YP, Saade GR, Romero R, Garfield RE. IgE-independent mast cell activation augments contractility of nonpregnant and pregnant guinea pig myometrium. Int Arch Allergy Immunol 2008; 147: 140-146.

23. Norrby K. Mast cells and angiogenesis. APMIS 2002; 110: 355-371.

24. Shelesnyak MC. Antihistamines and the ovum. Br Med J 1963; 16: 1268

25. Jensen F, Woudwyk M, Teles A, Woidacki K, Taran F, Costa S et al. Estradiol and progesterone regulate the migration of mast cells from the periphery to the uterus and induce their maturation and degranulation. PLoS One 2010; 5: e14409.

26. Murphy VE, Clifton VL, Gibson PG. Asthma exacerbations during pregnancy: incidence and association with adverse pregnancy outcomes. Thorax 2006; 61: 169-176.

27. Menzies FM, Higgins CA, Shepherd MC, Nibbs RJ, Nelson SM. Mast cells reside in myometrium and cervix, but are dispensable in mice for successful pregnancy and labor. Immunol Cell Biol 2011; 90: 321-329.

28. Michaloudi HC, Papadopoulos GC. Mast cells in the sheep, hedgehog and rat forebrain $J$ Anat 1999; 195: 269-276.

29. Scholten J, Hartmann K, Gerbaulet A, Krieg T, Müller W, Testa G et al. Mast cell- specific Cre/loxP-mediated recombination in vivo. Transgenic Res 2008: 17: 307-315.

30. Song H, Lim H, Paria BC, Matsumoto H, Swift LL, Morrow J et al. Cytosolic phospholipase A2 alpha is crucial for "on-time" embryo implantation that directs subsequent development. Development 2002; 129: 2879-2889.

31. Valent $\mathrm{P}$, Sillaber $\mathrm{C}$, Baghestanian M, Bankl HC, Kiener HP, Lechner $\mathrm{K}$ et al. What have mast cells to do with edema formation, the consecutive repair and fibrinolysis? Int Arch Allergy Immunol 1998; 115: 2-8.

32. Metz M, Maurer M. Mast cells-key effector cells in immune responses. Trends Immunol 2007; 28: 234-241.

33. Galli SJ. Mast cells and basophils. Curr Opin Hematol 2000; 7: 32-39.

34. Rabinovich GA, Croci DO. Regulatory circuits mediated by lectin-glycan interactions in autoimmunity and cancer. Immunity 2012; 36: 322-335.

35. von Wolff M, Wang X, Gabius HJ, Strowitzki T. Galectin fingerprinting in human endometrium and decidua during the menstrual cycle and in early gestation. Mol Hum Reprod 2005; 11: 189-194

36. Fischer I, Redel S, Hofmann S, Kuhn C, Friese K, Walzel H et al. Stimulation of syncytium formation in vitro in human trophoblast cells by galectin-1. Placenta 2010; 31: 825-832.

37. Zhao XJ, McKerr G, Dong Z, Higgins CA, Carson J, Yang ZQ et al. Expression of oestrogen and progesterone receptors by mast cells alone, but not lymphocytes, macrophages or other immune cells in human upper airways. Thorax 2001; 56: 205-211.

38. Dudeck A, Dudeck J, Scholten J, Petzold A, Surianarayanan S, Köhler A et al. Mast cells are key promoters of contact allergy that mediate the adjuvant effects of haptens. Immunity 2011; 34: 973-984.

39. Müsch W, Wege AK, Männel DN, Hehlgans T. Generation and characterization of alphachymase-Cre transgenic mice. Genesis 2008; 46: 163-166.
40. Feyerabend TB, Weiser A, Tietz A, Stassen M, Harris N, Kopf M et al. Cre-mediated cell ablation contests mast cell contribution in models of antibody- and $\mathrm{T}$ cell-mediated autoimmunity. Immunity 2011; 35: 832-844.

41. Aflalo ED, Sod-Moriah UA, Potashnik G, Har-Vardi I. Expression of plasminogen activators in preimplantation rat embryos developed in vivo and in vitro. Reprod Biol Endocrinol 2005; 3: 7

42. Oh CK. Mast cell mediators in airway remodeling. Chem Immunol Allergy 2005; 87: 85-100.

43. Carmeliet P, Schoonjans L, Kieckens L, Ream B, Degen J, Bronson R et al. Physiological consequences of loss of plasminogen activator gene function in mice. Nature 1994; 368: 419-424.

44. Labied S, Blacher S, Carmeliet P, Noël A, Frankenne F, Foidart JM et al. Transient reduction of placental angiogenesis in PAl-1-deficient mice. Physiol Genomics 2011; 43: 188-198.

45. Uzumcu M, Homsi MF, Ball DK, Coskun S, Jaroudi K, Hollanders JM et al. Localization of connective tissue growth factor in human uterine tissues. Mol Hum Reprod 2000; 6: 1093-1098.

46. Surveyor GA, Wilson AK, Brigstock DR. Localization of connective tissue growth factor during the period of embryo implantation in the mouse. Biol Reprod 1998; 59: 1207-1213.

47. Frazier K, Williams S, Kothapalli D, Klapper H, Grotendorst GR. Stimulation of fibroblast cell growth, matrix production, and granulation tissue formation by connective tissue growth factor. J Invest Dermatol 1996; 107: 404-411.

48. Miller DA, Lee A, Pelton RW, Chen EY, Moses HL, Derynck R. Murine transforming growth factor-beta 2 cDNA sequence and expression in adult tissues and embryos. Mol Endocrinol 1989; 3: 1108-1114.

49. Shull MM, Ormsby I, Kier AB, Pawlowski S, Diebold RJ, Yin M et al. Targeted disruption of the mouse transforming growth factor- $\beta 1$ gene results in multifocal inflammatory disease. Nature 1992; 359: 693-699.

50. Yamazaki M, Tsujimura T, Morii E, Isozaki K, Onoue H, Nomura S et al. C-kit gene is expressed by skin mast cells in embryos but not in puppies of Wsh/Wsh mice: agedependent abolishment of c-kit gene expression. Blood 1994; 83: 3509-3516.

51. Zenclussen AC, GerlofK, Zenclussen ML, Sollwedel A, Bertoja AZ, Ritter T et al Abnormal $T$ cell reactivity against paternal antigens in spontaneous abortion: adoptive transfer of pregnancy-induced $\mathrm{CD} 4+\mathrm{CD} 25+$ regulatory $\mathrm{T}$ cells prevents fetal rejection in a murine abortion model. Am J Pathol 2005; 166: 811-822.

52. Croy BA, Zhang J, Tayade C, Colucci F, Yadi H, Yamada AT. Analysis of uterine natural killer cells in mice. Methods Mol Biol 2011; 612: 465-503.

Cell Death and Disease is an open-access journal published by Nature Publishing Group. This work is licensed under the Creative Commons Attribution-NonCommercial-No Derivative Works 3.0 Unported License. To view a copy of this license, visit http://creativecommons.org/licenses/by-nc-nd/3.0/

Supplementary Information accompanies the paper on Cell Death and Disease website (http://www.nature.com/cddis) 